\title{
Biologia reprodutiva e polinização de Jacquemontia nodiflora (Desr.) G. Don (Convolvulaceae) em Caatinga na região de Petrolina, PE, Brasil
}

\author{
Lúcia Helena Piedade Kiill1,3 e Rosangela Simão-Bianchini ${ }^{2}$
}

Recebido: 21.05.2009; aceito: 10.11.2011

\begin{abstract}
Reproductive biology and pollination of Jacquemontia nodiflora (Desr.) G. Don (Convolvulaceae) in Caatinga, in Petrolina region, Pernambuco State, Brazil). The main objective of this work was to study aspects of pollination biology, behavior and frequency of flower visitors, reproduction and phenology of Jacquemontia nodiflora in Caatinga hiperxerófila, Petrolina, PE, from March 2004 to March 2005. The phenological data showed that the phenophases of budding, flowering and fruiting occurred mainly during the rainy season, while leaf senescence occured in the dry season, indicating the influence of precipitation in the process. The flowers are grouped in cymes, are small (10 $\mathrm{mm}$ diameter), shallow-campanulate, white, odorless and secrete small amount of nectar $(<1 \mu \mathrm{l})$. The anthesis is diurnal, occurring around $5 \mathrm{~h} 30 \mathrm{~min}$, and the lifetime of the flower is only nine hours. Throughout the flowering, the flowers are visited by bees, wasps and flies, and the bees Apis mellifera, Trigona spinipes and Frieseomelitta doederleini are the most frequent visitors $(47.7,26.0$ and $12.1 \%$ of total visits, respectively). The system of reproduction of $J$. nodiflora is facultatively autogamous, producing fruit by self-pollination (rates $>90 \%$ ) and by cross-pollination (75.6\%). Jacquemontia nodiflora can be considered as an important nectar source for medium and small bees, and A. mellifera, T. spinipes and F. doederleini were considered as pollinators of this species. Key words: Caatinga, floral biology, pollinatiors, reproductive system
\end{abstract}

RESUMO - (Biologia reprodutiva e polinização de Jacquemontia nodiflora (Desr.) G. Don (Convolvulaceae) em Caatinga na região Petrolina, PE, Brasil). O principal objetivo deste trabalho foi estudar aspectos da biologia da polinização, comportamento e frequência de visitantes florais, reprodução e fenologia de Jacquemontia nodiflora em área de Caatinga hiperxerófila, em Petrolina-PE, no período de março de 2004 a março de 2005. Os dados fenológicos mostraram que a brotação, floração e frutificação concentram-se na estação chuvosa, enquanto a senescência foliar ocorre na estação seca, indicando a influência de precipitação no processo de reprodução. As flores estão reunidas em cimeiras, são pequenas (10 mm de diâmetro), curto-campanuladas, brancas, inodoras e secretam pequena quantidade de néctar $(<1 \mu \mathrm{l})$. A antese é diurna, ocorrendo por volta das $5 \mathrm{~h} 30 \mathrm{~min}$., sendo o tempo de vida da flor apenas de nove horas. As flores são visitadas por abelhas, vespas e moscas, sendo as abelhas Apis mellifera, Trigona spinipes e Frieseomelitta doederleini os visitantes mais frequentes (47,7, 26,0 e 12,1\% do total de visitas, respectivamente). Quanto ao sistema de reprodução, J. nodiflora é autógama facultativa, produzindo frutos por autopolinização (taxas $>90 \%$ ) e por polinização cruzada $(75,6 \%)$. Jacquemontia nodiflora pode ser considerada como uma importante fonte de néctar para abelhas de tamanho médio e pequeno, sendo $A$. mellifera, $T$. spinipes e F. doederleini consideradas como polinizadores desta espécie.

Palavras-chave: biologia floral, Caatinga, polinizadores, sistema de reprodução

\section{Introdução}

Convolvulaceae é uma família monofilética (Judd et al. 1999, Stefanović et al. 2002, 2003), formada por plantas geralmente trepadeiras volúveis ou subarbustivas, com folhas sempre alternas. As flores possuem um par de bractéolas, deixando distintos pedúnculo e pedicelo, e apresentam cinco sépalas em geral livres e corola gamopétala de formas e cores variadas. A presença, em cada pétala, de uma

1. Embrapa Semiárido, Caixa Postal 23, 56.302-970 Petrolina, PE, Brasil

2. Instituto de Botânica, Caixa Postal 68041, 04045-972 São Paulo, SP, Brasil

3. Autor para correspondência: kiill@cpatsa.embrapa.br 
região central espessada, com nervuras mais evidentes (áreas mesopétalas) é também uma característica comum na família. Os estames são cinco, inclusos ou excertos, inseridos no tubo da corola, geralmente com a base do filete dilatada, apresentando tricomas ou glândulas e com anteras elipsoidais de deiscência longitudinal. $\mathrm{O}$ gineceu é formado por dois carpelos unidos, geralmente contendo dois óvulos por carpelo (Stefanović et al. 2003, Bianchini 2005).

No Brasil, Convolvulaceae está representada por cerca de 350 espécies, predominando os gêneros Ipomoea (118 espécies), Evolvulus (67) e Jacquemontia (54) (Simão-Bianchini \& Ferreira 2010). O gênero Jacquemontia caracteriza-se por possuir um estilete filiforme com dois estigmas apicais com forma estreito-ovóide a curto-elipsoidal, lembrando uma língua. A presença de tricomas estrelados nas folhas e de cápsulas 8-valvares também auxiliam no reconhecimento deste gênero (Robertson 1971).

De acordo com Giulietti et al. (2006), 21 espécies de Jacquemontia são relatadas para a Caatinga, das quais seis são citadas como de uso alimentício, entre elas, J. nodiflora (como J. confusa Meisn., sinônimo da espécie estudada). Esta convolvulácea, apesar de formar grandes populações em quase toda a Região Nordeste e em Minas Gerais (Bianchini 2002), tem sido pouco estudada. É caracterizada por apresentar hábito subarbustivo quando jovem, tornando-se trepadeira volúvel. As folhas são ovadas com base cordada a subcordada e ápice obtuso a agudo, com característicos tricomas estrelados de três ramos recobrindo os ramos, as folhas e parcialmente as sépalas. As flores são reunidas em inflorescências cimosas, geralmente densas, a corola pode ser desde branca até arroxeada. O fruto é do tipo cápsula, bilocular com deiscência longitudinal, septicida e loculicida, apresentando oito valvas.

Estudos sobre a ecologia da polinização de espécies de Convolvulaceae mostram que as abelhas são relatadas como os polinizadores mais frequentes (Kiill \& Ranga 2000b, 2003, 2004, Pick 2007, Pick \& Schlindwein 2011), embora haja registros de espécies polinizadas por borboletas, mariposas e pássaros (Machado \& Sazima 1987; Frey 1995). Quanto ao sistema de reprodução, na família ocorrem espécies autocompatíveis e auto-incompatíveis. Segundo Martin (1970), espécies de ciclo de vida anual, com flores pequenas a médias são, em geral, autocompatíveis e as espécies perenes com flores médias a grandes, são auto-incompatíveis.
Para o gênero Jacquemontia, poucas informações sobre ecologia da polinização estão registradas em literatura e, para a região das Caatingas, estudos dessa natureza são ainda mais raros. Kiill \& Ranga (2000a) relataram a associação de flores de $J$. multiflora com abelhas sem ferrão e a ocorrência de autocompatibilidade na espécie. Silva et al. (2010), em observações com J. montana (Moric.) Meisn. em Mucugê-BA, registraram machos e fêmeas de Dialictus spp. (Halictidae) como os visitantes mais frequentes, sendo considerados como polinizadores potenciais dessa espécie.

Diante da representatividade e importância biológica das convolvuláceas nas Caatingas, estudos voltados para o conhecimento da biologia reprodutiva são necessários. O presente trabalho teve por objetivo estudar a biologia floral, fenologia e sistemas de reprodução de Jacquemontia nodiflora em área de Caatinga hiperxerófila, na região semiárida de Pernambuco, visando contribuir com informações sobre a ecologia reprodutiva do gênero.

\section{Material e métodos}

Os trabalhos de campo foram desenvolvidos em área de Caatinga arbustiva-arbórea, hiperxerófila, pertencente à Embrapa Semiárido, situada no município de Petrolina, PE $\left(09^{\circ} 09^{\prime} \mathrm{S}, 40^{\circ} 22^{\prime} \mathrm{W}\right.$, altitude de $365,5 \mathrm{~m}$ e média pluviométrica anual de $570 \mathrm{~mm}$ ), no período de janeiro de 2004 a dezembro de 2005, com observações complementares de março a maio de 2006. De acordo com a classificação de Köppen, o clima da área se enquadra no tipo BSwh', definido como semiárido (chuva anual menor de $750 \mathrm{~mm}$ ), de vegetação xerófita (BS), apresentando inverno $\operatorname{seco}(\mathrm{w})$, temperatura do mês mais frio maior que $18{ }^{\circ} \mathrm{C}$ (h'), sem excesso hídrico.

Jacquemontia nodiflora ocorre por toda a área de estudo, sendo observada com mais frequência em locais abertos e nas bordas da Caatinga. Os indivíduos observados foram encontrados sobre arbustos e arvoretas nativas, e também sobre cercas. Por ser uma liana volúvel, cada emaranhado foi considerado como sendo um indivíduo.

Todos os trabalhos de campo foram desenvolvidos utilizando-se 20 indivíduos marcados de Jacquemontia nodiflora. Os estudos de fenologia foram realizados entre março de 2004 e março de 2005 em indivíduos observados a cada 15 dias ao longo do ciclo, anotando-se a presença ou ausência das fenofases 
de brotamento, floração (incluindo a presença de botões e de flores), frutificação (incluindo a presença de frutos imaturos e maduros) e senescência foliar (presença de folhas secas ou queda das folhas). O pico de um determinado evento fenológico foi considerado quando mais de 50\% dos indivíduos apresentavam a fenofase. Na figura 1A são apresentados os dados de precipitação para a região durante o período dos estudos fenológicos.

Quanto à morfologia, 20 flores de dez indivíduos foram coletadas e fixadas em álcool $70 \%$ e, posteriormente, foram tomadas medidas do comprimento e do diâmetro da corola, bem como do tamanho das estruturas reprodutivas e suas posições no interior da flor. Para as observações do horário da antese e tempo de vida da flor, 20 botões em pré-antese foram marcados e acompanhados até a queda da flor. Para verificar o número de flores produzidas por inflorescências, 20 cimeiras foram marcadas em cinco indivíduos, contabilizando-se o número total de flores abertas por dia.

A receptividade do estigma foi testada com peróxido de hidrogênio a 10 vol. (Zeisler 1938), em 20 flores recém abertas, em cinco indivíduos. Para avaliar a viabilidade dos grãos de pólen, lâminas foram preparadas segundo Radford et al. (1974), utilizando-se 10 botões em pré-antese, de três indivíduos. Cinco lâminas foram preparadas utilizando-se as cinco anteras, sendo que em cada uma foram amostrados 100 grãos de pólen, totalizando 500 grãos.

Para avaliar a quantidade de néctar produzido por flor, 10 inflorescências foram ensacadas em cinco indivíduos. As 20 flores abertas foram coletadas ao final da tarde para as tomadas do volume e concentração do néctar. Para medir a concentração de açúcares do néctar, foi utilizado um refratômetro digital Atago N1 (0 - 32\%). O volume de néctar foi avaliado com auxílio microseringas de $5 \mu \mathrm{L}$.

Os visitantes foram observados ao longo da floração, no período entre 5 e 16 horas, totalizando 60 horas de esforço amostral, sendo anotados a frequência, a duração e o horário de suas visitas, bem como o comportamento (recurso forrageado e contato com estruturas reprodutivas) dos visitantes mais frequentes. Para cada intervalo de observação com duração de uma hora, foram feitas, no mínimo, cinco repetições em dias não consecutivos. Observações após as 16 horas não foram realizadas, pois as flores já se apresentavam desidratadas e pouco atrativas, não sendo mais procuradas pelos visitantes florais.
De acordo com o comportamento apresentado, os visitantes foram considerados como polinizadores (Dafni 1992) ou pilhadores (Inouye 1980). Quanto à frequência, os visitantes foram considerados como abundantes (A) quando apresentaram frequência de visitas igual ou superior a $30 \%$; frequentes $(\mathrm{F})$ quando apresentaram frequência de visitas de $10 \%$ a $30 \%$, e raros $(\mathrm{R})$ quando estes apresentaram frequência inferior a $10 \%$. Alguns visitantes foram capturados, fixados e mantidos a seco, para posterior identificação e exame dos locais de deposição do pólen e, posteriormente, depositados no Laboratório de Ecologia da Embrapa Semiárido.

Para determinar o sistema reprodutivo da espécie, flores foram submetidas aos experimentos de autopolinização manual e espontânea, polinização cruzada e agamospermia. Para cada tratamento foram utilizadas 90 flores, selecionadas nos 20 indivíduos da população, sendo previamente ensacadas e emasculadas, quando necessário. O pólen utilizado em todos os testes foi obtido de flores previamente protegidas. Para os experimentos de polinização cruzada, foram utilizadas plantas localizadas a pelo menos cinco metros dos indivíduos receptores. Também foram marcadas e observadas 90 flores, sem nenhum tratamento, para determinar o sucesso da polinização em condições naturais, servindo como controle. Os frutos obtidos foram acompanhados até a maturação. As frequências de frutos formados foram comparadas aplicando-se o teste estatístico Qui-quadrado $\left(\chi^{2}\right)$. Materiais botânicos foram depositados no Herbário do Trópico Semiárido (HTSA 2265) e duplicatas no herbário do Instituto de Botânica (SP), para servirem como testemunha.

\section{Resultados e Discussão}

A fenofase de brotamento em Jacquemontia nodiflora ocorreu ao longo do período de observações, sendo registrada ausência ou baixa produção de folhas apenas no auge do período seco (agosto a outubro de 2004). Os picos da produção de folhas novas ocorreram de março a julho de 2004 e de novembro de 2004 a março de 2005. Já a senescência foliar ocorreu principalmente na estação seca, com um pico entre setembro e novembro (figura 1B). Dessa forma, J. nodiflora poderia ser considerada como uma espécie decídua que, na estação seca, reduz a produção de folhas novas e aumenta a senescência foliar, diminuindo assim a perda de água por evapotranspiração. 

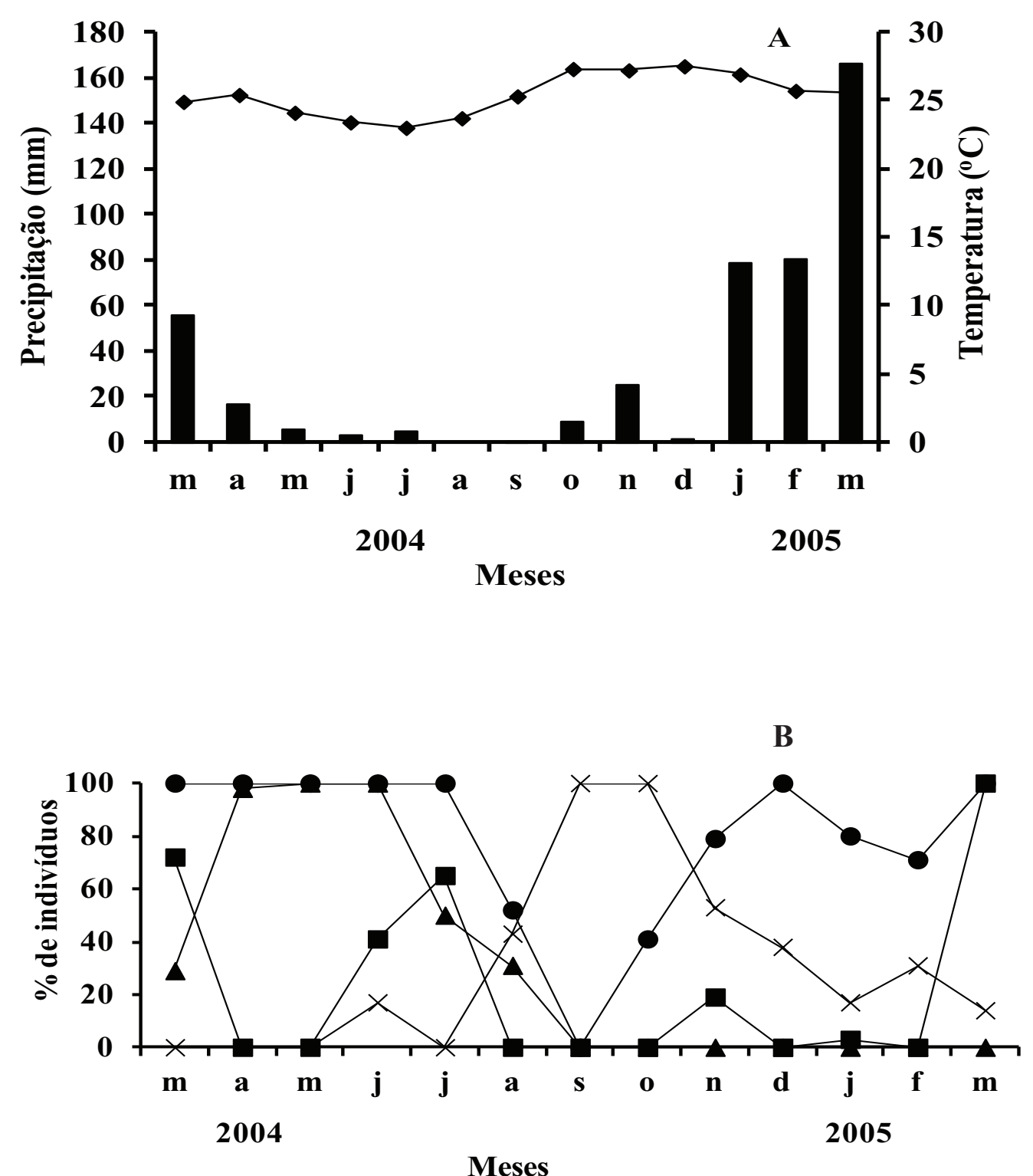

- brotamento $\rightarrow$ floração $\rightarrow$ frutificação $\quad \nsucc$ senescência

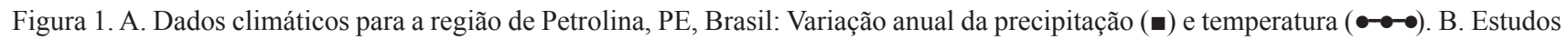
fenológicos de 20 indivíduos de Jacquemontia (Desr.) G.Don.

Figure 1. A. Climatic data for the region of Petrolina,PE, Brazil: Anual variation of preciptation ( $\mathbf{\square})$ and temperature ( $\bullet-\bullet)$. B. Fenological estudies of 20 individuals of Jacquemontia (Desr.) G.Don.

A fenofase de floração foi caracterizada por três picos em meados ou final da estação chuvosa, enquanto a produção de frutos foi concentrada no final da estação chuvosa, com pico entre abril e junho, quando todos os indivíduos apresentavam esta fenofase. Comparando as fenofases de floração e frutificação em 2004, verificou-se que dos dois picos de produção de flores dos quais foi possível observar a frutificação, março de 2004 e junho de 2004, somente o primeiro levou efetivamente a formação de frutos maduros. Assim, somente a floração do período chuvoso seria funcional.

$\mathrm{O}$ fato das fenofases de brotamento, floração e frutificação ocorrerem principalmente na estação 
chuvosa, enquanto a senescência ocorreu no auge do período seco, sugere que a sazonalidade na precipitação é um fator controlador dos eventos fenológicos na espécie. Fato semelhante foi registrado para Jacquemontia multiflora (Choisy) Hallier f. (Kiill \& Ranga 2000a), bem como para outras espécies de Convolvulaceae da Caatinga (Kiill \& Ranga 2000b, 2003, 2004). Nesse ecossistema, a influência das condições climáticas sobre os eventos fenológicos é visível, com respostas rápidas, sendo que a precipitação age como um gatilho para dar início à produção de folhas novas, flores e frutos (Barbosa et al. 2003).

As flores de Jacquemontia nodiflora estão reunidas em inflorescências terminais do tipo cimeira, com média de $14 \pm 4$ botões por inflorescência $(n=20)$. A disponibilidade diária de flores por inflorescência variou de duas até seis flores/inflorescência/dia. Por apresentar produção diária de muitas flores por planta, com elevada sincronia intra-específica e floração em uma única estação do ano, essa espécie pode ser considerada como pertencente ao padrão de floração do tipo cornucópia (cf. Gentry 1974) ou ao tipo anual intermediário de floração (cf. Newstrom \& Frankie 1994). O padrão de floração do tipo cornucópia foi registrado para J. multiflora (Kiill \& Ranga 2000a) bem como para outras lianas (Guedes et al. 2009). Segundo Machado (1990) e Machado et al. (1997), esse mesmo padrão de floração foi registrado para espécies arbóreas e arbustivas da Caatinga, indicando que a produção em massa de flores poderia ser uma estratégia para atrair o polinizador nesses ambientes mais secos.

A antese de mais de uma flor por inflorescência por dia é outro mecanismo que pode aumentar a atratividade dos indivíduos de J. nodiflora, aumentando a oferta de recursos florais disponíveis para o forrageamento. Tal estratégia também foi encontrada para J. multiflora (Kiill \& Ranga 2000a) e J. montana (Silva et al. 2010), bem como para outras espécies da Caatinga (Machado 1990, Kiill \& Ranga 2003, 2004). A apresentação das flores em inflorescências associada à sua produção maciça pela planta, faz com que os atrativos primários como cor e odor sejam maximizados, além de implicar em maior oferta de recompensa floral por vôo do polinizador (Richards 1986).

As flores de $J$. nodiflora são gamopétalas, actinomorfas, curto-campanuladas e inodoras. A corola apresenta, em média, $4 \pm 0,72 \mathrm{~mm}$ de diâmetro na porção basal do tubo e $10 \pm 1,28 \mathrm{~mm}$ de comprimento, coloração branca, com a porção basal e áreas mesopétalas em tom levemente arroxeado, funcionando como guias de néctar. $\mathrm{O}$ androceu é formado por cinco estames heterodínamos e com anteras bitecas, dorsifixas. O gineceu é formado por um ovário súpero, bicarpelar, tetraovulado, com dois óvulos por lóculo, estiletes fundidos e estigma bilobado. Os verticilos reprodutivos são de coloração branca e ficam dispostos no centro da flor (figura 2A). O nectário apresenta-se na forma de um disco hipógino e esponjoso.

Assim, as flores dessa Convolvulaceae podem ser classificadas como pequenas, de formato aberto, simetria radial e com órgãos de reprodução expostos no centro da flor, morfologia floral semelhante àquela apresentada por outras espécies do gênero (Kiill \& Ranga 2000a; Silva et al. 2010). De acordo com Machado \& Lopes (2003), espécies com flores pequenas e do tipo disco são bem representadas na Caatinga, com 23,7 e 25,7\%, respectivamente. Quanto à simetria, as autoras registraram a predominância das flores actinomorfas (61,7\%). Segundo Percival (1969) e Faegri \& Pijl (1980), esse formato aberto da corola, juntamente com a localização central das estruturas reprodutivas e o fácil acesso ao néctar, permite que as flores sejam visitadas por muitos tipos de visitantes que, uma vez pousados, podem coletar néctar e pólen sem nenhuma dificuldade. Essa flexibilidade com relação a diferentes polinizadores é vantajosa para a planta, especialmente em ambientes com condições desfavoráveis e sujeitos as variações climáticas extremas, como as encontradas na região do presente estudo.

A antese das flores de Jacquemontia nodiflora foi registrada por volta das $5 \mathrm{~h} 30 \mathrm{~min}$., sendo o processo de abertura caracterizado pelo lento afastamento das bordas da corola, que se destorcem, evidenciando a prefloração imbricada torcida. Nesta fase, os grãos de pólen estão disponíveis nas anteras e apresentam alta viabilidade $(98,6 \%)$, o estigma está receptivo e há acúmulo de pequena quantidade de néctar (inferior a $1 \mu \mathrm{L} /$ flor) na base da corola. As flores permanecem inalteradas até as $14 \mathrm{~h}$, quando se inicia a desidratação das bordas da corola, caracterizando o início da senescência floral. Por volta das $16 \mathrm{~h}$ as flores se apresentam totalmente murchas, pouco atrativas, porém a queda dos elementos florais pode ocorrer até 24 horas após a antese, exceto o ovário e o cálice, quando há fecundação. O tempo de vida das flores é de 10 horas, podendo ser consideradas como flores 
efêmeras, cuja curta duração pode estar relacionada à ocorrência da polinização, sinalizando ao visitante que as mesmas, por já terem sido fertilizadas, não precisam ser mais visitadas (Percival 1969). Esse mesmo padrão foi encontrado em outras espécies do gênero (Kiill \& Ranga 2000a, Silva et al. 2010) como em outras convolvuláceas da Caatinga (Kiill \& Ranga, 2000b, 2003, 2004, Pick \& Schlindwein 2011).

Por apresentar atributos florais como antese diurna, corola de cores vivas (branca); produção de néctar em pequenas quantidades e oculto na base da corola, guias de néctar, plataforma de pouso para o visitante, $J$. nodiflora pode ser considerada como possuindo flores melitófilas (Faegri \& Pij1 1979), concordando com o padrão descrito para outras convolvuláceas (Kiill \& Ranga 2000a, b, 2003, 2004, Silva et al. 2010). Os levantamentos das síndromes de polinização em espécies da Caatinga demonstram que há predominância de entomofilia, especialmente da melitofilia, em relação às demais síndromes, sendo que, nesse ecossistema as espécies apresentam, na sua maioria, flores pequenas e generalistas, com cores claras, e pouco vistosas, oferecendo principalmente néctar como recompensa floral (Machado \& Lopes 2002).

As flores da $J$. nodiflora foram visitadas por cinco espécies de abelhas, vespas e moscas (tabela 1). Entre as abelhas, Apis mellifera L. foi responsável por $47,7 \%$ do total de visitas, sendo considerada abundante, enquanto Trigona spinipes Fabr., com 26,0\% e Frieseomelitta doederleini Friese, com $12,1 \%$, foram consideradas frequentes. As visitas da Vespa sp. 1 e de Diptera sp. 1 foram consideradas raras, com percentuais de $7,8 \%$ e $6,4 \%$ dos totais de visitas, respectivamente.

Ao longo do dia, foram registradas visitas das cinco espécies, porém verificou-se que $A$. mellifera foi mais frequente em todos os horários, com número de visitas que variaram de 71 a 99. Comparando o padrão de visitação das três abelhas, verificou-se que, enquanto $A$. mellifera manteve constantes suas visitas ao longo do dia, $T$. spinipes e $F$. doederleini concentraram suas visitas no período de $10 \mathrm{~h}$ às $11 \mathrm{~h} e$ de $11 \mathrm{~h}$ às $15 \mathrm{~h}$, respectivamente. As visitas do díptera foram mais frequentes no início da manhã e das vespas no final da manhã e início da tarde (figura 3). De modo geral, verificou-se que os picos de visitação de A. mellifera e das duas espécies de abelhas sem ferrão foram inversamente proporcionais, indicando possível competição por interferência entre polinizadores. Considerando que $A$. mellifera é uma espécie exótica e que não atuava originalmente como polinizador de $J$. nodiflora, a presença desta abelha poderia estar deslocando os polinizadores da espécie.

Quanto ao recurso floral forrageado, os visitantes florais de $J$. nodiflora coletaram apenas néctar (tabela 1), diferindo do comportamento encontrado para $J$. multiflora e $J$. montana, nas quais, segundo Kiill \& Ranga (2000a) e Silva et al. (2010), visitantes florais forrageavam néctar e/ou pólen. Quanto ao comportamento, após a aproximação da flor, $A$. mellifera pousava sobre a corola, dirigia-se para o centro da flor e introduzia a probóscide entre as bases dos filetes para ter acesso à câmara nectarífera. Nessa ocasião, a abelha contatava as anteras e o estigma com a cabeça e a parte dorsal do tórax (figura 2B), onde o pólen ficava depositado (polinização nototríbica). Concluída a coleta de néctar, que durava de 2 a 4 segundos/flor, as abelhas abandonavam a flor, visitando flores próximas na mesma inflorescência ou então abandonavam o indivíduo.

Trigona spinipes e $F$. doederleini apresentaram comportamento semelhante ao descrito para A. mellifera, tocando as estruturas reprodutivas durante as visitas e, por isso, podem ser consideradas como polinizadores de $J$. nodiflora. Já a Vespa sp. 1 e o díptera sp. 1 não contatavam os órgãos sexuais das flores durante suas visitas, sendo considerados como pilhadores de néctar (tabela 1).

Padrão semelhante de coleta de néctar foi descrito para A. mellifera e T. spinipes, em J. multiflora (Kiill \& Ranga, 2000a). Essas abelhas têm sido consideradas como insetos de comportamento oportunístico e generalista, sendo relatadas também como polinizadores de outras espécies de Convolvulaceae ocorrentes na Caatinga (Kiill \& Ranga 2000b, 2003, 2004). Para esse ecossistema, Machado (1990) relata que as abelhas foram consideradas polinizadores efetivos em $77,4 \%$ os táxons estudados, sendo $A$. mellifera e $T$. spinipes as espécies mais expressivas.

Os resultados obtidos com os experimentos de polinização estão na tabela 2 e mostram que não houve formação de frutos apomíticos em J. nodiflora, indicando que a agamospermia não ocorre nessa espécie, o que concorda com as observações feitas para outras convolvuláceas da Caatinga (Kiill \& Ranga 2000a, b, 2003, 2004). As taxas obtidas com polinização cruzada foram inferiores às de autopolinização e em condições naturais e a análise estatística (tabela 2) indicou que há diferença entre esses tratamentos. A formação de menor quantidade de 

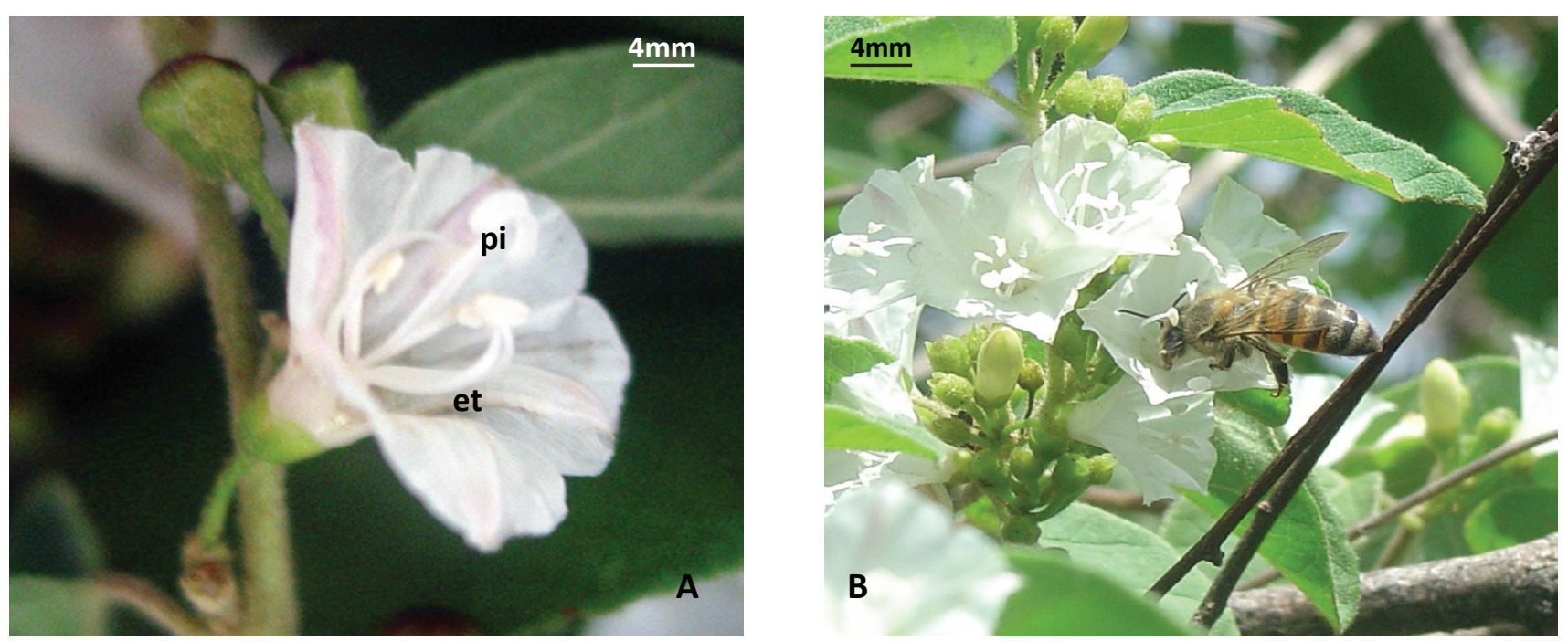

Figura 2. A. Vista lateral de uma flor de Jacquemontia nodiflora (Desr.) G.Don evidenciando o formato da corola e a posição dos estames (et) e pistilos (pi). B. Vista lateral de uma abelha (Apis mellifera) coletando néctar em uma flor em área de Caatinga hiperxerófila, Petrolina, PE.

Figure 2. A. Side view of a flower of Jacquemontia nodiflora (Desr.) G.Don showing the shape of the corolla and the position of stamens (et) and pistil (pi). B. Side view of a bee (Apis mellifera) collecting nectar in a flower in an area of the caatinga hiperxerófila, in Petrolina, Pernambuco State, Brazil.

Tabela 1. Visitantes florais de Jacquemontia nodiflora (Desr.) G.Don com suas frequências de visitas e recurso forrageado em cinco dias de observação, no período de $5 \mathrm{~h}$ às $16 \mathrm{~h}$, em Petrolina, $\mathrm{PE}$, Brasil. Frequência: Abundantes $(\mathrm{A})$ frequências de visitas $\geq$ a 30\%; Frequentes (F) frequências de visitas de 10 a 30\% e Raros (R) frequências $<$ a $10 \%$. Eficiência na polinização: po- polinizador; pi-pilhador.

Table 1. Floral visitors of Jacquemontia nodiflora (Desr.) G.Don with their frequency of visits and foraged resource in five days of observation during the 05h00a.m. to $16 \mathrm{~h} 00$ p.m., in Petrolina, Pernambuco State, Brazil. Frequency: Abundant (A) frequency of visits $\geq$ to $30 \%$; Frequently (F) frequency of visits by 10 to $30 \%$ and Rare (R) frequency $<$ to $10 \%$. Efficiency in pollination: pollinator (po); nectar thieving (nt).

\begin{tabular}{lllll}
\hline \multicolumn{1}{c}{ Espécie } & $\mathrm{N}^{\circ}$ de visitas & Frequência & Eficiência na polinização & Recurso Forrageado \\
\hline Apis mellifera L. & 823 & $\mathrm{~A}$ & po & $\mathrm{N}$ \\
Trigona spinipes Fabr. & 448 & $\mathrm{~F}$ & po & $\mathrm{N}$ \\
Frieseomelitta doederleini Friese & 209 & $\mathrm{~F}$ & po & $\mathrm{N}$ \\
Vespa sp. 1 & 135 & $\mathrm{R}$ & pi & $\mathrm{N}$ \\
Diptera sp.1 & 110 & $\mathrm{R}$ & pi & $\mathrm{N}$ \\
\hline Total & 1725 & & & \\
\hline
\end{tabular}

frutos por xenogamia pode ser atribuída à manipulação das flores, tanto no processo de retirada das anteras, como no momento da transferência do pólen para o estigma, podendo ocasionar danos ao gineceu. Por outro lado, as taxas registradas em condições naturais indicam que há eficiência dos agentes polinizadores. Desta forma, J. nodiflora pode ser considerada como autógama facultativa, produzindo frutos e sementes tanto por autopolinização, como por polinização cruzada, concordando com as informações encontradas para outras convolvuláceas da Caatinga (Kiill \& Ranga 2000a, b).

Jacquemontia nodiflora apresenta atributos florais que permitem classificá-la como melitófila, sendo sua polinização realizada por abelhas generalistas. De acordo com Faegri \& Van Der Pijl (1980) e Percival (1969), essa espécie poderia ser considerada como uma espécie oligofílica, de polinização promíscua, uma vez que os visitantes têm fácil acesso aos recursos florais. A espécie é autocompatível, apresentando altas 
taxas de frutificação tanto por autopolinização como por polinização cruzada.

Por apresentar floração ao longo do ano, Jacquemontia nodiflora pode ser considerada como uma importante fonte de néctar para as abelhas de médio e pequeno porte, sendo Trigona spinipes, Frieseomelitta doederleini e Apis mellifera consideradas como polinizadores dessa espécie.

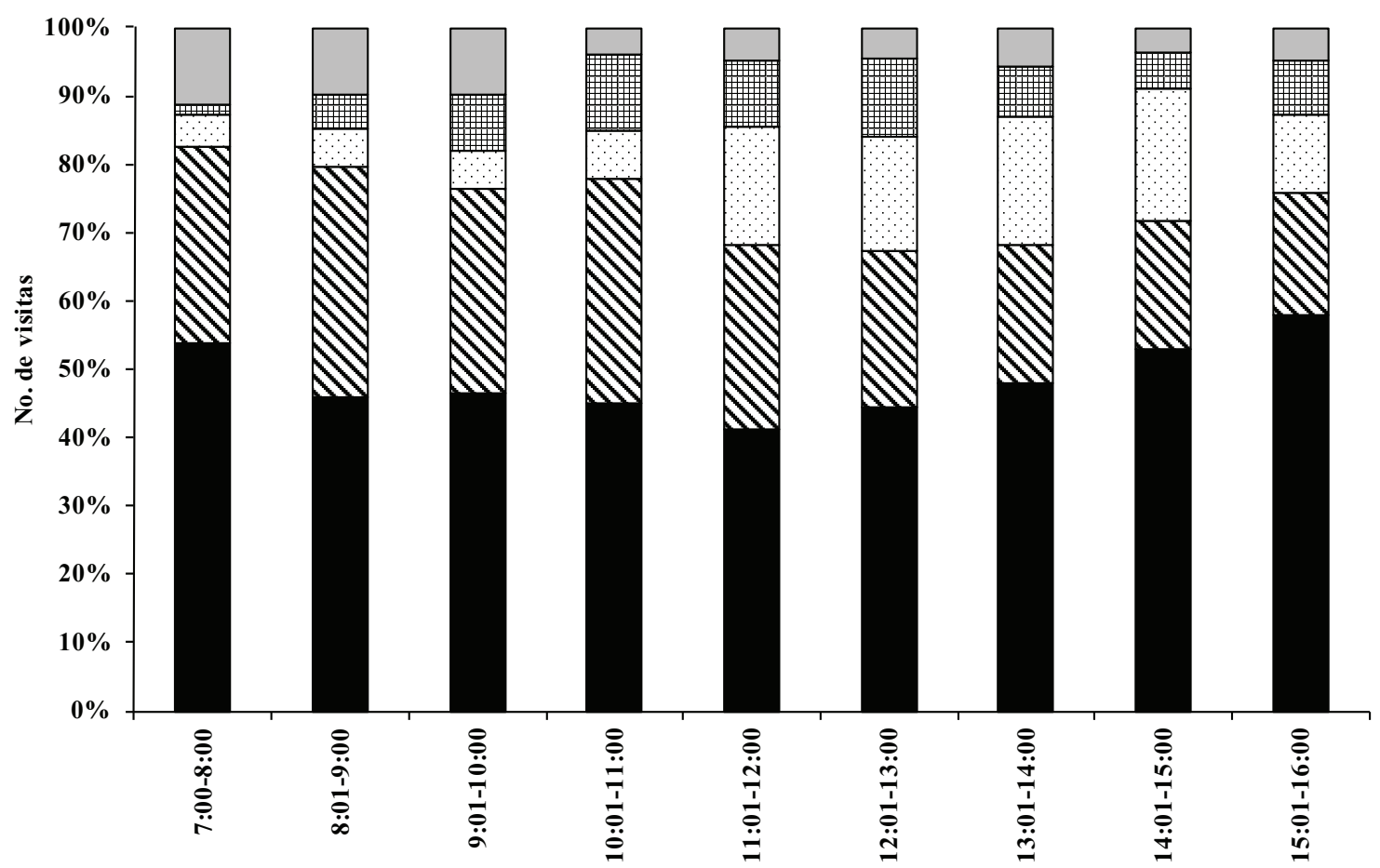

Horas do Dia

Figura 3. Número de visitas por visitante, em cada intervalo de tempo, registrado para as flores de Jacquemontia nodiflora observados em área de Caatinga hiperxerófila, Petrolina, PE, Brasil. Apis mellifera, Trigona spinipes, $\square$ Frieseomelitta doederleini, $\mathbf{⿴ 囗 十}$ Vespa sp. 1, $\square$ Diptera sp. 1.

Figure 3. Number of visits per visitor in each time interval, registered to the flowers of the Jacquemontia nodiflora observed in the area of caatinga hiperxerófila, Petrolina, Pernambuco State, Brazil. $\square$ Apis mellifera, $\mathbf{9}$ Trigona spinipes, $\square$ Frieseomelitta doederleini, 田 Vespa sp. 1, $\square$ Diptera sp. 1 .

Tabela 2. Resultados dos experimentos de polinização de Jacquemontia nodiflora em aérea de Caatinga hiperxerófila, Petrolina, PE.

Table 2. Results of experiments of pollination of Jacquemontia nodiflora in "caatinga hiperxerófila", Petrolina, Pernambuco State, Brazil.

\begin{tabular}{lccc}
\hline \multicolumn{1}{c}{ Experimento de polinização } & No. de flores & No. de frutos & $\%$ \\
\hline Apomixia & 90 & 0 & 0 \\
Condições naturais & 90 & $89 \mathrm{a}$ & 99,4 \\
Autopolinização espontânea & 90 & $86 \mathrm{a}$ & 97,3 \\
Autopolinização manual & 90 & $82 \mathrm{a}$ & 91,5 \\
Polinização cruzada & 90 & $68 \mathrm{~b}$ & 75,6 \\
\hline
\end{tabular}

Valores seguidos de mesma letra na coluna não diferem pelo teste qui-quadrado $\left(\chi^{2}\right)$, com 1 grau de liberdade e $\alpha=5 \%$. 


\section{Literatura citada}

Barbosa, D.C.A., Barbosa, M.C.A., Lima, L.C.M. 2003. Fenologia de espécies lenhosas da Caatinga. In: I.R. Leal, M.Tabarelli \& J.M.C. Silva, (eds.). Ecologia e conservação da Caatinga. Editora Universitária da Universidade Federal de Pernambuco, Recife, pp. 657-694.

Bianchini, R.S. 2002. Distribuição das espécies de Convolvulaceae na Caatinga. In: E.V.S.B. Sampaio, A.M. Giulietti, J. Virginio \& C.F.L. Gamarra-Rojas (eds.). Vegetação e flora da Caatinga. Associação Plantas do Nordeste/Centro Nordestino de Informações sobre Plantas, Recife, pp.133-136.

Bianchini, R.S. 2005. Convolvulaceae. In: M.M.R.F. Melo, F. Barros, S.A.C. Chiea, M. Kirizawa, S.L. Jung-Mendaçolli \& M.G.L. Wanderley (eds.). Flora Fanerogâmica da Ilha do Cardoso, v. 11. Instituto de Botânica, São Paulo, pp. 129-146.

Dafni, A. 1992. Pollination ecology: a practical approach. Oxford University Press, New York.

Faegri, K. \& Van Der Pijl, L. 1980. The principles of pollination ecology. Pergamon Press, Oxford.

Frey, R. 1995. Ipomoea carnea ssp. fistulosa (Martius ex Choisy) Austin: Taxonomy, biology and ecology reviewed and inquired. Tropical Ecology 36: 21-48.

Guedes, R.S., Quirino, Z.G.M. \& Gonçalves, E.P. 2009. Fenologia reprodutiva e biologia da polinização de Canavalia brasiliensis Mart. ex Benth (Fabaceae). Biotemas 22: 27-37.

Gentry, A. H. 1974. Flowering phenology and diversity in tropical Bignoniaceae. Biotropica 6: 64-68.

Giulietti, A.M., Conceição, A. \& Queiroz, L.P. 2006. Diversidade e caracterização das fanerógamas do Semi-Árido brasileiro v. 1. Associação Plantas do Nordeste, Recife.

Inouye, D.W. 1980. The terminology of floral larceny. Ecology 61: 1251-1253.

Judd, W.S., Campbell, C.S., Kellog, E.A. \& Stevens, P.F. 1999. Plant Systematics: A phylogenetic approach. Sinauer Associates, Sunderland.

Kiill, L.H.P. \& Ranga, N.T. 2000a. Biologia floral e sistema de reprodução de Jacquemontia multiflora (Choisy) Hallier f. (Convolvulaceae). Revista Brasileira de Botânica 23: 37-43.

Kiill, L.H.P. \& Ranga, N.T. 2000b. Biologia da polinização de Merremia aegyptia (L.) Urb. (Convolvulaceae) no sertão de Pernambuco. Naturalia 25: 149-158.

Kiill, L.H.P. \& Ranga, N.T. 2003. Ecologia da polinização de Ipomoea asarifolia (Ders.) Roem. \& Schult. (Convolvulaceae) na região semi-árida de Pernambuco. Acta Botanica Brasilica 17: 355-362.
Kiill, L.H.P. \& Ranga, N.T. 2004. Biologia da reprodução de Turbina cordata (Choisy) Austin \& Staples (Convolvulaceae) no sertão Pernambucano. Sitientibus, série Ciências Biológicas 4: 14-19.

Machado, I.C.S. 1990. Biologia floral de espécies de Caatinga no município de Alagoinha (PE). Tese de Doutorado, Universidade Estadual de Campinas, Campinas.

Machado, I.C.S. \& Sazima, M. 1987. Estudo comparativo da biologia floral em duas espécies invasoras: Ipomoea hederifolia e I. quamoclit (Convolvulaceae). Revista Brasileira de Biologia 47: 425-436.

Machado, I.C.S., Barros, L.M. \& Sampaio E.V.S.B. 1997. Phenology of caatinga species at Serra Talhada, PE, Northeastern Brazil. Biotropica 29: 57-68.

Machado, I.C.S. \& Lopes, A.V. 2002. A polinização em ecossistema de Pernambuco: uma revisão do estado atual do conhecimento. In: M. Tabarelli \& J.M.C. Silva (orgs.). Diagnóstico da Biodiversidade de Pernambuco. Secretaria de Ciência e Tecnologia e Meio Ambiente, Fundação Joaquim Nabuco, Editora Massangana, Recife, pp. 583-596.

Machado, I.C.S. \& Lopes, A.V. 2003. Recursos florais e sistemas de polinização e sexuais em Caatinga. In: I.R. Leal, M. Tabarelli \& J.M.C. Silva (eds.). Ecologia e conservação da Caatinga. Editora Universitária da Universidade Federal de Pernambuco, Recife, pp. 515-563.

Martin, F.W. 1970. Self- and interespecific incompatibility in the Convolvulaceae. Botanical Gazzette 131: 130-144.

Newstrom, L.E. \& Frankie, W. 1994. A new classification for plant phenology based on flowering patterns in lowland tropical rain forest trees at La Selva, Costa Rica. Biotropica 26: 141-159.

Percival, M.S. 1969. Floral biology. Pergamon Press, London.

Pick, R.A. 2007. Comunidade de abelhas e plantas do Vale do Catimbau, Pernambuco e a relação entre abelhas Emphorini (Apidae) e espécies de Convolvulaceae. Tese de Doutorado, Universidade Federal da Paraíba, João Pessoa.

Pick, R.A. \& Schlindwein, C. 2011. Pollen partitioning of three species of Convolvulaceae among oligolectic bees in the Caatinga of Brazil. Plant Systematics and Evolution 293:147-159.

Radford, A.E., Dickinson, W.C., Massey, J.R. \& Bell, C.R. 1974. Vascular plant systematics. Harper \& Row, New York.

Richards, A.J. 1986. Plant breeding systems. Unwin \& Allem, London.

Robertson, K.R. 1971. Arevision of the genus Jacquemontia (Convolvulaceae) in North and Central America and the West Indies. Ph. D. Dissertation, Washington University, St Louis. 
Simão-Bianchini, R. \& Ferreira, P.P.A. 2010. Convolvulaceae. In: R.C. Forzza (Org.). Catálogo de plantas e fungos do Brasil. CNCflora, Jardim Botânico do Rio de Janeiro, Rio de Janeiro, pp. 882-894.

Silva, F.O., Kevan, S.D., Roque, N., Viana, B.F. \& Kevan, P.G. 2010. Records on floral biology and visitors of Jacquemontia montana (Moric.) Meisn. (Convolvulaceae) in Mucugê, Bahia. Brazilian Journal of Biology 70: 671-676. Disponível em <http://www. scielo.br/scielo.php?script=sci_arttext\&pid $=$ S1519$69842010000300027 \& \operatorname{lng}=\mathrm{pt \& nrm}=\mathrm{iso}>$. (acesso em 20.01.2011).
Stefanović, S., Krueger, L. \& Olmstead, R.G. 2002. Monophyly of the Convolvulaceae and circumscription of their major lineages based on DNA sequences of multiple choroplast loci. American Journal of Botany 89: 1510-1522.

Stefanović, S., Austin, D.F. \& Olmstead, R.G. 2003. Classification of Convolvulaceae: a phylogenetic approachment. Systematic Botany 28: 797-806.

Zeisler, M. 1938. Ueber die Abgrenzung der eigentlichen: Narben flaechen mit der Hilfe von Reaktionen. Beihefte zum Botanische Zentralblatt 58: 308-318. 